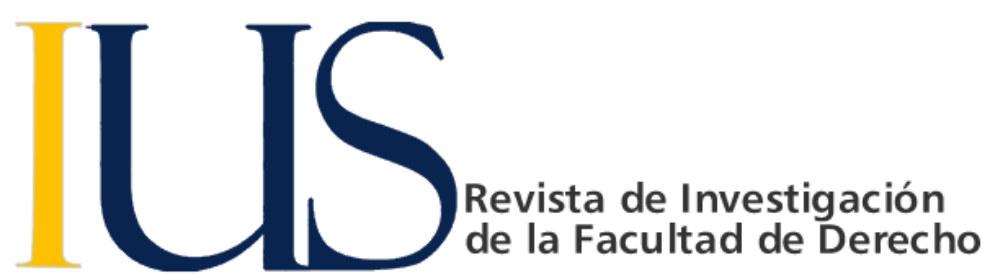

\title{
El control de las cláusulas abusivas en el Código de Protección y defensa del consumidor
}

\author{
Tony Daniel Barturén Llanos ${ }^{1}$
}

\section{INFORMACIÓN DEL ARTÍCULO}

Historia del artículo:

Recibido el 23 de mayo de 2011

Aceptado el 15 de junio de 2011

\section{Palabras clave:}

Código Civil

Comunidad Económica Europea

Cláusulas Generales de Contratación INDECOPI

Tribunal Constitucional

\section{RESUMEN}

Los contratos de consumo que vinculan a consumidores y proveedores en torno a la adquisición de bienes y/o servicios a cambio de un retribución económica, limitan la libertad contractual de los consumidores pues su contenido es pre redactado unilateralmente por el proveedor, sin embargo son necesarios en las sociedades modernas pues reducen los costos de transacción, esto es, tiempo, dinero y esfuerzo, que genera la contratación, pero exponen a los consumidores a las denominadas cláusulas abusivas, esto es, aquellas estipulaciones que en contra del principio de la buena fe objetiva colocan al consumidor en una situación de desventaja limitando sus derechos, de allí que el Estado deba establecer mecanismos de control a fin de evitar la existencia de dichas clausulas en la contratación en masa, a lo cual no es ajeno el Código de Protección y Defensa del Consumidor.

\section{Control of abusive clauses in the Consumer Protection and Defense Code}

\section{Introducción}

El 02.10.2010 entró en vigencia del Código de Protección y Defensa del Consumidor (Ley № 29571) con las excepciones previstas en la cuarta disposición complementaria final-, el mismo que entre otros aspectos regula el contrato de consumo y las cláusulas abusivas, supuestos vinculados a lo que tradicionalmente se ha denominado como contratación en masa.

Al respecto debemos recordar que en nuestro Código Civil de 1984 se han regulado los contratos por adhesión (artículo 1390) y las cláusulas generales de contratación (artículo 1392), distinguiendo entre estas últimas, las aprobadas por autoridad administrativa (artículo 1393) y las no aprobadas por autoridad administrativa (artículo 1397); asimismo, se ha establecido un listado de cláusulas que son calificadas como invalidas y que constituirían lo que conocemos como cláusulas abusivas, vejatorias o leoninas (artículo 1398), sin embargo, se carece de una definición sobre cláusulas abusivas y se omiten varios supuestos más que calificarían como clausulas vejatorias, además se restringe la existencia de cláusulas abusivas solo al caso de las cláusulas contenidas en un contrato por adhesión y a las clausulas generales de contratación no aprobadas administrativamente, con lo cual se excluye la posibilidad de la existencia de cláusulas abusivas cuando fueron objeto de una previa revisión y posterior aprobación administrativa.

Asimismo, hay que señalar que a través de la Ley de Protección al Consumidor - Decreto Legislativo № 716 (1991), si bien se reconocieron los derechos de los consumidores y se establecieron los deberes de los proveedores, sin embargo se omitió normas respecto de las cláusulas abusivas; luego con el Decreto Legislativo № 1045, Ley Complementaria del Sistema de

\footnotetext{
${ }^{1}$ Profesor de los cursos Derecho de las Obligaciones y Derecho de los Contratos I en la Universidad Católica Santo Toribio de Mogrovejo. Chiclayo, Perú.
} 
Protección al Consumidor (26.06.2008), y posteriormente con el TUO de la Ley de Protección al Consumidor, aprobado por D.S.№ 006-2009-PCM, se pretendió regular de un modo más preciso las cláusulas abusivas en los contratos de consumo, sin embargo como señala Roger Merino Acuña "existía una total falta de organicidad en nuestro sistema de control de cláusulas vejatorias: muchos cuerpos legales que regulan a medias y defectuosamente" ${ }^{\prime 2}$.

Como se aprecia, la regulación jurídica de la contratación de consumo ha evolucionado en los últimos veinticinco años y parece haber llegado a su punto culminante con la promulgación del Código de Protección y Defensa del Consumidor; por ello a través del presente trabajo se pretende analizar la normatividad contenida en el Código referida a los contratos de consumo, y específicamente identificar los mecanismos de control de las cláusulas abusivas, a efectos de analizar si estos resultan ser idóneos para evitar que se lesionen los derechos de los consumidores o se establezcan situaciones de desventaja o desigualdad en su perjuicio.

\section{AUTONOMÍA PRIVADA Y CONTRATACIÓN TRADICIONAL}

\subsection{Contrato Tradicional}

El concepto tradicional de contrato se sustenta en tres pilares básicos y fundamentales : a) el contrato como expresión de la autonomía privada; b) el contrato como acto jurídico celebrado por sujetos que actúan en igualdad de condiciones y con total libertad; y, c) el contrato como vínculo jurídico que obliga a las partes celebrantes al cumplimiento de sus propios términos (pacta sunt servanda).

Como señala Alfredo Bullard, "el concepto moderno de contrato no es más que un subproducto de la ideología liberal imperante a fines del siglo XVIII y principios del XIX. Se pensaba que la iniciativa individual era el mejor medio para el logro de la auténtica convivencia humana. Si se dejaba a la libertad actuar, todo sería mejor. Así se acuñan tres ideas centrales, íntimamente ligadas: la

\footnotetext{
2 Merino Acuña, Roger, El sistema de desprotección al consumidor, apuntes críticos desde la comparación jurídica, En Actualidad Jurídica, № 186, Lima, Perú, p. 68.

${ }^{3}$ Alfredo Bullard Gonzales, Contratación en Masa. ¿Contratación?, En Estudios de Análisis Económico del Derecho, ARA Editores, 1996, Lima, Perú, p. 53-54.

${ }^{4}$ Fernando de Trazegnies, El derecho civil ante la post-modernidad, En : Derecho № 45, Diciembre 1991, Lima, Perú, p. 289.

${ }^{5}$ Luis Diez-Picazo, Fundamentos del derecho civil patrimonial, Vol. I, Editorial Civitas, Madrid, 1996, p. 122.

${ }^{6}$ La autonomía privada es el poder jurídico que el ordenamiento jurídico otorga a los sujetos de derecho para autorregular sus
}

autonomía de la voluntad, la igualdad entre las partes y la obligatoriedad del acuerdo..." ${ }^{3}$

El concepto tradicional de contrato corresponde a lo que Fernando de Trazegnies denomina como modernidad, esto es, "una forma concreta de sociedad, que corresponde a la que la tradición occidental ha vivido y desarrollado en los últimos tres siglos,...la sociedad que conocemos como moderna dentro del mundo occidental.." ${ }^{4}$ y que se caracteriza por una exaltación de lo individual y subjetivo, de la libertad y de la racionalidad, de modo que la modernidad termina por configurarse con los ingredientes propios del racionalismo, liberalismo e individualismo.

Luis Diez-Picazo refiere que la concepción moderna del contrato tiene su raíz y fundamento en tres presupuestos ideológicos y sociológicos, "el primero de estos presupuestos es el presupuesto económico de una economía liberal fundada en el lema laissez faire y en la idea de que las leyes del mercado y el egoísmo individual actuando en el propio interés son, como dice Adam SMITH, los mejores motores de la felicidad y de la prosperidad de las naciones; el segundo de los presupuestos ideológicos.. se encuentra en la idea de la sustancial igualdad de las partes contratantes.. el tercero de los presupuestos ideológicos y socio económicos se encuentra en una época que rinde culto, como ya hemos señalado, a las ideas de la preponderancia de la libertad individual..."

\subsection{Derecho a la libre contratación.}

Uno de los pilares fundamentales sobre los que se erige el concepto tradicional de contrato es el de igualdad y libertad jurídica. Así, con relación al contrato tradicional se ha señalado que en ejercicio de la autonomía privada $^{6}$, los sujetos de derecho tienen libertad para decidir el momento y lugar de celebración de un contrato y elegir a su co-contratante (libertad de contratar), así como establecer el contenido u objeto del contrato (libertad contractual), encontrándose limitada su actuación por el orden público y las buenas costumbres. $^{7}$

intereses privados a través de la celebración de actos jurídicos y contratos lícitos.

7 Constitución Política del Perú, Artículo 2.- Derechos fundamentales de la persona: "Toda persona tiene derecho: ... 14. A contratar con fines lícitos, siempre que no se contravengan leyes de orden público."

Código Civil Peruano, Artículo 1354.- Contenido de los contratos: "Las partes pueden determinar libremente el contenido del contrato, siempre que no sea contrario a norma legal de carácter imperativo." 
El Tribunal Constitucional refiriéndose al derecho a la libre contratación consagrado en el inciso 14) del artículo 2 de la Constitución Política, ha manifestado que es "el acuerdo o convención de voluntades entre dos o más personas naturales y/o jurídicas para crear, regular, modificar o extinguir una relación jurídica de carácter patrimonial. Dicho vínculo -fruto de la concertación de voluntades- debe versar sobre bienes 0 intereses que poseen apreciación económica, tener fines lícitos y no contravenir las leyes de orden público. Tal derecho garantiza, prima facie: Autodeterminación para decidir la celebración de un contrato, así como la potestad de elegir al cocelebrante. Autodeterminación para decidir, de común acuerdo, la materia objeto de regulación contractual." ${ }^{8}$

\subsection{Contrato y acuerdo de voluntades.}

Se ha afirmado también que el contrato es el acuerdo de voluntades de dos o más partes destinado a la producción de efectos jurídicos patrimoniales, definición consagrada en el artículo 1351 de nuestro Código Civil. ${ }^{9}$

Así, se refiere que el contrato es el resultado de la integración recíproca de dos declaraciones de voluntad, unilaterales y recepticias, la oferta y la aceptación, que conforman una declaración conjunta de voluntad común. ${ }^{10}$

De otro lado, se ha indicado que el contrato es el negocio jurídico de autorregulación de intereses privados con contenido patrimonial, resultado de todo un proceso de negociaciones o tratativas, más o menos extensas y complejas -dependiendo del contenido del contrato-, realizadas por sujetos de derecho que actúan en igualdad de condiciones y con total libertad; es decir, en el iter contractual podemos identificar hasta tres etapas : negociación, celebración y ejecución, las mismas que deben desarrollarse en estricta observancia del principio de buena $\mathrm{fe}^{11}$; en consecuencia, la posibilidad de negociar con total libertad y en igualdad las estipulaciones o cláusulas que regirán la relación jurídica patrimonial, constituye la esencia misma del contrato.

\subsection{Costos de transacción en la contratación tradicional.}

Desde la segunda mitad del Siglo XX, el contrato como tradicionalmente lo entendemos, esto es, como

\footnotetext{
8 EXP. N.o 0008-2003-AI/TC - LIMA, Sentencia de fecha 11 de noviembre del 2003, fundamento 26.

${ }^{9}$ Código Civil Peruano, Artículo 1351.- Noción de contrato: "El contrato es el acuerdo de dos o más partes para crear, regular, modificar o extinguir una relación jurídica patrimonial."
}

expresión de la actuación de la autonomía privada, de la negociación de sus estipulaciones y de la posterior autorregulación de intereses entre sujetos de derecho libres e iguales, enfrenta una serie de cuestionamientos como consecuencia del surgimiento de la denominada contratación en masa o contratación estandarizada, la misma que se caracteriza por la ausencia de previa negociación del contenido contractual, pues las estipulaciones son impuestas por una de las partes en detrimento de la otra.

En una sociedad moderna caracterizada por un cambio en la organización del trabajo y en la producción, esto es, por una estandarización o producción en serie de bienes y servicios que concurren al mercado, la contratación tradicional no responde a las exigencias del mercado pues genera una serie de costos de transacción que pueden incidir en el precio de los productos o servicios.

Uno de estos costos de transacción está referido al tiempo, dinero y recursos humanos que se utilizan en la negociación de las condiciones del contrato, etapa fundamental dentro del proceso de formación del contrato tradicional. La negociación implica invertir tiempo en participar de las discusiones que generalmente anteceden a la celebración de un contrato; asimismo, se dedica tiempo a la revisión de documentos y de los diferentes proyectos de contrato, a efectos de llegar a acuerdos iniciales respecto, por ejemplo, de quien debe asumir la responsabilidad en caso de daños; finalmente, las negociaciones largas, las marchas y contramarchas, la demora en la celebración del contrato, genera también lo que se denomina costo negativo de oportunidad, esto es, la pérdida del rendimiento potencial de los recursos involucrados en la negociación, pues por ejemplo el tiempo que se pierde en negociar impediría obtener beneficios por la realización de la actividad que se pretende iniciar luego de la contratación. De otro lado, para la celebración de un contrato probablemente se requerirá contar con los servicios de un abogado, que se encargara de revisar la documentación necesaria para la celebración del contrato y de la redacción del documento contractual, lo cual genera un costo económico representado por el honorario profesional. Finalmente, dado que la negociación permite a las partes intervinientes expresar con libertad sus ideas, preferencias o intereses, un mismo proveedor tendría que negociar y celebrar

\footnotetext{
${ }^{10}$ Manuel De La Puente y Lavalle, Estudios del Contrato Privado, Tomo I, Cultural Cuzco S.A., Lima, Perú, 1983, pag 136.

${ }^{11}$ Código Civil Peruano, Artículo 1362.- Buena Fe: “Los contratos deben negociarse, celebrarse y ejecutarse según las reglas de la buena fe y común intención de las partes."
} 
contratos sobre los mismos bienes o servicios con cada uno de los potenciales consumidores o usuarios, con condiciones y clausulas distintas, lo cual encarecería los costos de ejecución de los contratos.

Al respecto señala Bullard "imaginemos al Presidente de la General Motors negociando, bajo la asesoría de un conjunto de abogados, todos los contratos de compraventa de automóviles que celebra la empresa. La burocratización administrativa, el tiempo y recursos perdidos, las demoras en la colocación de los automóviles en el mercado, las dificultades para interpretar y en su caso poder cubrir los posibles incumplimientos de los particulares referidos a relaciones jurídicas de contenido tan diverso, hubieran hecho imposible el eficiente desarrollo que esta empresa ha alcanzado en el presente siglo.."12

Como se aprecia, la previa negociación de los términos contractuales encarece el mercado y lo torna ineficiente, de allí la necesidad de reducir los costos de transacción, pues como afirma Bullard "en una sociedad de masas, con un mercado generalizado y masivo, los costos de transacción se multiplican geométricamente en relación al número de transacciones necesarias. Si en cada transacción que se da en el mercado los costos de transacción fuesen elevados, la consecuencia podría ser la inviabilidad del propio mercado. Bienes y servicios como el transporte público, los restaurantes, los seguros, los bancos, los supermercados, los teatros, los cines, las playas de estacionamiento, los colegios, las universidades, los hoteles, los parques de diversiones, los sistemas de ahorro colectivo, etc., no serían viables si no existieran formas de reducir los costos de transacción que los afectan..."13

En consecuencia, el surgimiento de la contratación estandarizada obedece a la necesidad de que en una sociedad de consumo y de economía de mercado, se reduzcan o eliminen los costos de transacción que la contratación tradicional genera y que pueden encarecer el precio de los productos y servicios que se ofrecen en el mercado.

\section{CONTRATO Y RELACIÓN DE CONSUMO}

\footnotetext{
${ }^{12}$ Alfredo Bullard Gonzales, Contratación en Masa ¿Contratación?, op. cit. p. 56.

${ }^{13}$ Alfredo Bullard Gonzales, ¡Firme primero, lea después! La contratación masiva y la defensa del consumidor, op. cit. p. 241.

${ }^{14}$ Código Civil Peruano, Artículo 1390.- Contrato por adhesión: “EI contrato es por adhesión cuando una de las partes, colocada en la alternativa de aceptar o rechazar íntegramente las estipulaciones fijadas por la otra parte, declara su voluntad de aceptar."

15 Código Civil Peruano, Artículo 1392.- Cláusulas generales de contratación : “Las cláusulas generales de contratación son aquéllas
}

\subsection{El contrato por adhesión y las cláusulas generales de contratación.}

Nuestro Código Civil de 1984 no contiene una definición de contrato de consumo, pero si alude al contrato por adhesión ${ }^{14}$ y a las cláusulas generales de contratación ${ }^{15}$, como herramientas jurídicas de contratación en masa.

En el contrato por adhesión, una de las partes predispone o redacta, en forma anticipada o no, la totalidad del contenido del contrato, y la otra parte solo tiene la posibilidad de adherirse al reglamento contractual o no celebrar el contrato. Aunque la celebración del contrato no es fruto de la negociación entre las partes, pues no existe libertad contractual del lado de la parte no predisponente, sin embargo se señala que subsiste la libertad de contratar pues no existe la obligación de contratar, salvo el caso de los contratos necesarios por adhesión, como por ejemplo para la prestación de los servicios públicos, en los cuales generalmente existe un solo proveedor del mismo y consecuentemente el consumidor no tiene la posibilidad de escoger entre celebrar o no el contrato, pues si decide no celebrar el contrato estaría renunciando a la posibilidad de contar con ese servicio público esencial para su vida de relación personal y familiar.

Las cláusulas generales de contratación constituyen un reglamento contractual elaborado por una de las partes contratantes, con la finalidad de uniformizar el contenido de futuros contratos que se celebren en base a ellas; adquieren fuerza vinculante y carácter contractual desde que se incorporan al documento contractual, y se caracterizan por su predisposición unilateral y su generalidad, además deben estar redactadas en forma clara, precisa y sencilla, para facilitar su comprensión directa.

Si bien se puede afirmar que a diferencia de los contratos por adhesión, en los contratos con cláusulas generales de contratación es posible excluir o incorporar cláusulas en interés de la parte no predisponente ${ }^{16}$, sin embargo se debe considerar que "en ambos supuestos contratos (por adhesión y por cláusulas generales de contratación), siempre una parte termina adhiriéndose -en menor o mayor medida- al

redactadas previa y unilateralmente por una persona o entidad, en forma general y abstracta, con el objeto de fijar el contenido normativo de una serie indefinida de futuros contratos particulares, con elementos propios de ellos."

${ }^{16}$ Código Civil Peruano, Artículo 1395.- Exclusión de cláusulas generales del contrato : "Las partes pueden convenir expresamente que determinadas cláusulas generales de contratación aprobadas por la autoridad administrativa, no se incorporen a la oferta en el contrato particular que ellas celebran." 
programa contractual predispuesto por la otra. La adhesión es pues un elemento común de estos contratos, constituyendo su característica principal.." 17

\subsection{Contrato de consumo y relación de consumo}

A diferencia del Código Civil de 1984, en el Código de Protección y Defensa del Consumidor se ha regulado el denominado contrato de consumo señalándose en el artículo 45 que "el contrato de consumo tiene como objeto una relación jurídico patrimonial en la cual interviene un consumidor y un proveedor para la adquisición de productos o servicios a cambio de una contraprestación económica."

La relación jurídica patrimonial a la cual se alude no es otra que la relación de consumo la misma que conforme a lo establecido en el artículo IV del Título Preliminar del Código"es la relación por la cual un consumidor adquiere un producto o contrata un servicio con un proveedor a cambio de una contraprestación económica."

En el documento denominado "Lineamientos 2006 de la Comisión de Protección al Consumidor", aprobado por Resolución Nº01-2006-LIN-CPC/INDECOPI, se señala que toda relación de consumo está determinada por la concurrencia de tres componentes: un consumidor o usuario, un proveedor, y un producto o servicio materia de una transacción comercial. Al respecto, en el articulo IV del Título Preliminar del Código de Protección y Defensa del Consumidor, se define a los consumidores o usuarios como "las personas naturales o jurídicas que adquieren, utilizan o disfrutan como destinatarios finales productos 0 servicios materiales e inmateriales, en beneficio propio o de su grupo familiar o social, actuando así en un ámbito ajeno a una actividad empresarial o profesional. No se considera consumidor para efectos de este Código a quien adquiere, utiliza o disfruta de un producto o servicio normalmente destinado para los fines de su actividad como proveedor. Los microempresarios que evidencien una situación de asimetría informativa con el proveedor respecto de aquellos productos o servicios que no formen parte del giro propio del negocio"; asimismo, se señala que los proveedores son "las personas naturales o jurídicas, de derecho público o privado, que de manera habitual fabrican, elaboran, manipulan, acondicionan, mezclan, envasan, almacenan, preparan, expenden, suministran productos o prestan servicios de cualquier naturaleza a

17 MERINO ACUÑA, Roger Arturo, "Cláusulas vejatorias y autonomía contractual en el Código Civil y las leyes especiales", Cuadernos Jurisprudenciales, $N^{\circ}$ 64, Octubre 2006, Año 6, pag. 5. los consumidores"; finalmente se establece que producto "es cualquier bien mueble o inmueble, material o inmaterial, de origen nacional o no" y que servicio "es cualquier actividad de prestación de servicios que se ofrece en el mercado, inclusive de naturaleza bancaria, financiera, de crédito, de seguros, previsionales y los servicios técnicos y profesionales." Como se aprecia, en los términos del Código el contrato de consumo es aquél que tiene por objeto la relación de consumo, esto es, una relación intersubjetiva que vincula a proveedor y consumidor, los mismos que ocupan posiciones o situaciones jurídicas subjetivas, y que constituye "una relación jurídica compleja que comprende una serie de derechos y deberes que van más allá de la adquisición del producto o de la utilización del servicio y que se pueden dar durante o después de dicho acto de adquisición o de utilización."18

Sobre la denominación "contrato de consumo", es cuestionable que el legislador pretenda explicar esta nueva realidad social, el de las relaciones de consumo, utilizando los esquemas teóricos de la contratación clásica, pues se denomina "contrato" a aquello que claramente no corresponde a las características del contrato tradicional, pues las relaciones de consumo no son fruto de la negociación o del acuerdo libre y voluntariamente alcanzado entre proveedor y consumidor, sino que se caracterizan por ser relaciones jurídicas estandarizadas.

Como señala Bullard, "la teoría tradicional ha hecho y sigue haciendo, verdaderos malabares para tratar de explicar, dentro de sus categorías, las distintas manifestaciones de este fenómeno. Como dijimos, sigue buscando oferentes, aceptantes, consentimientos, buena fe, etc. Creemos que la contratación en masa ha rebasado por completo los marcos de la concepción tradicional de contrato con lo que quedan dos posibles salidas: o le damos al concepto contrato un contenido distinto al de ser un simple acuerdo de voluntades, para poder englobar a la llamada contratación en masa, o creamos una nueva terminología que permita explicar a cabalidad este nuevo fenómeno." ${ }^{19}$

\subsection{Relaciones de consumo y reducción de costos de transacción}

La contratación de consumo, sea por adhesión o con arreglo a clausulas generales de contratación, se caracteriza por:

18 ESPINOZA ESPINOZA, Juan, "Derecho de los Consumidores", Editorial Rodhas, agosto, 2006, Lima, Perú, pag.42

${ }^{19}$ Alfredo Bullard Gonzales, Contratación en Masa ¿Contratación?, op. cit. p. 58. 
a) La predisposición unilateral de las condiciones 0 estipulaciones, esto es, una sola de las partes proveedor-prerredacta o predispone anticipadamente o no el contenido de las estipulaciones o reglas de conducta que han de regir la relación de consumo y a las cuales se somete el consumidor o usuario.

b) La generalidad y abstracción de las condiciones o estipulaciones, pues las mismas se elaboran no pensando en un sujeto en particular, sino en un sinnúmero de consumidores, potenciales usuarios de los productos y servicios, y pretenden incorporarse como reglas de conducta a todas las futuras transacciones o intercambios que un mismo proveedor piensa realizar con un conjunto de consumidores anónimos.

c) La inevitabilidad de la aplicación o imposibilidad de negociación, pues la aplicación y exigibilidad de las condiciones, estipulaciones o reglas de conducta, en las transacciones que un consumidor pretende realizar con un proveedor, no puede ser evitada si quiere recibir el bien o servicio de que se trate; el consumidor encuentra seriamente limitado y en algunos inexistente su poder de negociación de las reglas o estipulaciones que han de regir la relación de consumo.

Precisamente, la estandarización de las condiciones, estipulaciones o reglas de conducta que rigen las relaciones de consumo y por ello relaciones jurídicas estandarizadas, constituye el mecanismo más importante de reducción de los costos de transacción en que se incurre con la contratación tradicional, pues reducir o limitar la negociación y permitir que los proveedores redacten con anticipación un conjunto uniforme de condiciones, a través de formularios preimpresos u otros similares, que luego serán incorporados y regirán un sinnúmero de relaciones de consumo que surgirán en el futuro, evita que se encarezca artificialmente el mercado.

Los consumidores actuando racionalmente renuncian a su libertad de negociación para reducir así los costos de transacción que las negociaciones tradicionales ocasionan, evitando que los mismos se trasladen probablemente al precio de los productos o servicios que requieran, o impidiendo que se desincentive la fabricación o producción de bienes o la prestación de servicios por la incidencia de costos de transacción. En consecuencia, la regulación jurídica de los contratos y relaciones de consumo en el Código de Protección y Defensa del Consumidor, obedece a la exigencia de una sociedad de consumo y de una economía de mercado que busca la maximización de los beneficios y la consecuente reducción de los costos de transacción que pueden hacer ineficiente el mercado.

\section{PROTECCIÓN JURÍDICA DE LOS DERECHOS DE LOS CONSUMIDORES}

El Tribunal Constitucional, en los considerandos de la Sentencia emitida con fecha 17.01.2005 en el proceso constitucional de amparo seguido por Agua Pura Rovic S.A.C. contra el Instituto de Defensa de la Competencia y de la Propiedad Intelectual $\left(\right.$ INDECOPI) ${ }^{20}$, señaló que "el consumidor o usuario deviene en el fin de toda actividad económica; es decir, es quien concluye el círculo económico satisfaciendo sus necesidades y acrecentando su bienestar a través de la utilización de los productos y servicios ofertados en el mercado. En puridad, se trata de una persona natural o jurídica que en virtud de un acto jurídico oneroso adquiere, utiliza o disfruta de determinados productos (como consumidor) o servicios (como usuario) que previamente han sido ofrecidos al mercado."

Asimismo, el Tribunal Constitucional ha referido que el artículo 65 de la Constitución "prescribe la defensa de los consumidores y usuarios, a través de un derrotero jurídico binario; a saber: a) Establece un principio rector para la actuación del Estado; b) Consigna un derecho personal y subjetivo."

Afirma también el Tribunal Constitucional, que este derrotero jurídico binario "se sustenta en una pluralidad de principios, entre los cuales cabe mencionar los siguientes: a) El principio pro consumidor; b) El principio de proscripción del abuso del derecho; c) El principio de isonomia real; d) El principio restitutio in íntegrum; e) El principio de transparencia; f) El principio de veracidad; g) El principio indubio pro consumidor; h) El principio pro asociativo."

Finalmente, el Tribunal Constitucional manifiesta que en atención a los principios antes señalados, surgen dos obligaciones para el Estado," a) Garantizar el derecho a la información sobre los bienes y servicios que están a su disposición en el mercado. Ello implica la consignación de datos veraces, suficientes, apropiados y fácilmente accesibles; b) Velar por la salud y la seguridad de las personas en su condición de consumidores o usuarios. Ello implica que se asegure que los productos y servicios ofertados en el mercado deben ser tales que, utilizados en condiciones normales o previsibles, no pongan en peligro la salud y seguridad de los consumidores o usuarios."

Al respecto, debe tenerse en consideración que los derechos de los consumidores antes mencionados, no son los únicos que garantiza la Constitución, pues como

\footnotetext{
${ }^{20}$ EXP. N. ${ }^{\circ} 3315-2004-A A / T C$
} 
indica el propio Tribunal Constitucional, "pese a que existe un reconocimiento expreso de los derechos anteriormente señalados, estos no son los únicos que traducen la real dimensión de la defensa y tuitividad consagrada teleológicamente en la Constitución. Es de verse que, insertos en el texto supra, albergan implícita o innominadamente una pluralidad de derechos que, siendo genéricos en su naturaleza, y admitiendo manifestaciones objetivamente incorporadas en el mismo texto fundamental, suponen la existencia de un numerus apertus a otras expresiones sucedáneas."

El Código de Protección y Defensa del Consumidor desarrolla legislativamente el precepto constitucional antes señalado, estableciendo como principio rector de la política social y económica del Estado, en un régimen de economía social de mercado, la protección de los derechos de los consumidores, para lo cual desarrolla en el artículo $\vee$ del título preliminar una serie de principios $^{21}$, consagra derechos de los consumidores (artículo 1.1) precisando que los mismos no se agotan en la enumeración contenida en dicha norma sino que se extiende a los demás derechos que reconoce el Código u otras leyes especiales (artículo 1.2), siendo nula la renuncia a los mismos y todo pacto en contrario (artículo 1.3), establece el deber de los proveedores de proporcionar al consumidor información relevante sobre los productos y servicios ofertados (artículo 2), así como el deber de garantizar la idoneidad y calidad de los productos y servicios que ofrecen (artículo 18), entre otros aspectos.

Estos derechos que constituyen un mínimo indispensable para la tutela de los consumidores, pueden sin embargo ser vulnerados por los proveedores a través de la inclusión en las relaciones de consumo de las denominadas cláusulas abusivas o leoninas, de allí la necesidad de establecer mecanismos de control de las mismas.

\section{LAS CLÁUSULAS ABUSIVAS EN EL CÓDIGO DE PROTECCIÓN DEFENSA DEL CONSUMIDOR}

El Código Civil no contiene una definición de cláusula abusiva y tampoco existía disposición similar en el Decreto Legislativo № 716 - Ley de Protección al Consumidor; es recién con el Decreto Legislativo №

\footnotetext{
21 1. Principio de soberanía del consumidor; 2. Principio pro consumidor; 3. Principio de transparencia; 4. Principio de corrección de la asimetría; 5 . Principio de buena fe; 6 . Principio de protección mínima; 7. Principio pro asociativo; 8. Principio de primacía de la realidad.

${ }^{22}$ Elaborado por la Comisión de Juristas Presidida por el Dr. Jorge Avendaño Valdéz y publicado en el Diario Oficial El Peruano, el 11.04.2006.
}

1045 - Ley Complementaria del Sistema de Protección al Consumidor, que se establecen algunas disposiciones aplicables a los contratos de consumo, entre ellas una suerte de definición genérica de cláusula abusiva, señalándose en el artículo 18 que "en los contratos entre consumidores y proveedores : $a$. No podrán incluirse cláusulas que impongan obstáculos onerosos o desproporcionados para el ejercicio de los derechos reconocidos al consumidor en los contratos."

Como antecedente hay que señalar que en el documento denominado Propuestas de Reformas del Código Civil ${ }^{22}$, al plantearse la modificación del actual artículo 1398 del Código Civil, se calificaba en general como cláusula vejatoria a "...cualquier estipulación que cause, en detrimento de la otra parte, un desequilibrio importante entre los derechos y las obligaciones de los contratantes que contravenga el principio de la buena fe."

El Código de Protección y Defensa del Consumidor contiene en su artículo 49.1 una definición de cláusula abusiva, similar a lo dispuesto en el artículo 3.1 de la Directiva 93/13/CEE ${ }^{23}$, señalando que se entiende por cláusulas abusivas "todas aquellas estipulaciones no negociadas individualmente que, en contra de las exigencias de la buena fe, coloquen al consumidor, en su perjuicio, en una situación de desventaja o desigualdad o anulen sus derechos."

Como se aprecia, en el Código de Protección y Defensa del Consumidor se considera cláusula abusiva aquella estipulación:

- Que no hubiera sido negociada previamente entre las partes, en consecuencia no serán vejatorias las clausulas o componentes de las mismas que hubieran sido negociadas con el consumidor, teniendo el proveedor la carga de la prueba de dicha situación. Al respecto el artículo 49.3 del Código establece que "el hecho de que ciertos elementos de una clausula o que una clausula aislada se haya negociado individualmente no excluye la aplicación de las normas sobre cláusulas abusivas al resto del contrato. El proveedor que afirme que una determinada clausula ha sido negociada individualmente asume la carga de la prueba". Sobre el particular señala Teresa Tovar Mena

${ }^{23} \mathrm{Se}$ define como cláusulas abusivas a "las cláusulas contractuales que no se hayan negociado individualmente ... si, pese a la exigencias de la buena fe, causan en detrimento del consumidor un desequilibrio importante entre los derechos y obligaciones de las partes que se derivan del contrato". 
que "la razón de ser de la sanción de ineficacia de las clausulas vejatorias es restituir el equilibrio contractual cuando el predisponente, precisamente por gozar de esa posición, ha redactado clausulas a su favor o en contra de la otra parte, generando un desequilibrio de derechos y obligaciones. Pero, si una clausula no fue preredactada por el proveedor, sino negociada y acordada individualmente con el consumidor, no existe razón para deshacer tal desequilibrio si lo hubiere" ${ }^{\prime 24}$. Al respecto debió incorporarse en el Código de Protección y Defensa del Consumidor una disposición como la contenida en el artículo 3.2., primer párrafo, de la Directiva 93/13/CEE ${ }^{25}$, para considerar que la existencia de negociación individual no necesariamente debe conllevar a la modificación por el consumidor de la cláusula propuesta por el proveedor, sino a la posibilidad del consumidor de ejercer tal modificación, de modo que como señala Juan Espinoza Espinoza "nos encontraremos frente a una negociación individual solo cuando el profesional haya dado al consumidor una posibilidad concreta y efectiva de incidir en el contenido del contrato. Así, una discusión a la cual no haya seguido una modificación, debe considerarse suficiente índice de negociación individual, toda vez que resulte, de la manera en la cual la discusión se ha desenvuelto, que la renuncia a la modificación haya sido el fruto de una elección consciente del consumidor". ${ }^{26}$

- Que genere un desequilibrio en perjuicio del consumidor de los derechos y obligaciones que derivan del contrato, contrario al principio de buena fe, debiendo entenderse que se refiere a la buena fe objetiva, esto es a la infracción de los deberes jurídicos de corrección, de lealtad, de probidad, en consecuencia en tanto el desequilibrio que pudiera presentarse no entre en colisión con tal principio, la cláusula no sería considerada abusiva.

Asimismo, en el artículo 49.2 del Código de Protección y Defensa del Consumidor, al igual que en la Directiva 93/13/CEE ${ }^{27}$, se han establecido tres criterios que se

\footnotetext{
${ }^{24}$ Tovar Mena, Teresa V., Cláusulas abusivas en los contratos de consumo, En Actualidad Jurídica, № 186, Gaceta Jurídica Editores, 200..., Lima, Perú, p. 46.

25 Articulo 3.2.- "...haya sido redactada -la cláusula- y el consumidor no haya podido influir sobre su contenido, en particular en el caso de los contratos de adhesión."

${ }^{26}$ Espinoza Espinoza, Juan, op. cit., pag.171.

${ }^{27}$ Articulo 4.1.- ...el carácter abusivo de una cláusula contractual se apreciará teniendo en cuenta la naturaleza de los bienes o servicios que sean objeto del contrato y considerando, en el momento de la celebración del mismo, todas las circunstancias que concurran en su celebración, así como todas las demás
}

deben considerar para calificar o determinar cuándo nos encontramos frente a una cláusula abusiva :

a) la naturaleza de los productos o servicios objeto del contrato;

b) todas las circunstancias que concurren en el momento de su celebración, incluida la información que se haya brindado; $y$,

c) todas las demás cláusulas del contrato o de otro del que este dependa.

El ultimo criterio no estaba consignado en la Ley Complementaria del Sistema de Protección al Consumidor, a pesar que si lo establecía la legislación comparada, y sin embargo es relevante pues como refiere Teresa Tovar Mena "una clausula vista aisladamente puede ser considerada abusiva o vejatoria pero puede que ello no ocurra si es analizada sistemáticamente" 28 . Al respecto debemos recordar que el artículo 169 del Código Civil consagra como una regla de interpretación del acto jurídico y consecuentemente del contrato, la interpretación sistemática. $^{29}$

Finalmente, hubiera sido importante que se incorporara en el Código de Protección y Defensa del Consumidor una disposición como la contenida en el artículo 4.2. de la Directiva 93/13/CEE $E^{30}$, a efectos de interpretar que el desequilibrio no está referido al análisis de los valores económicos que representan prestación y contraprestación, sino al desequilibrio entre las posiciones jurídicas subjetivas de las partes, que genera perjuicio al consumidor.

En conclusión, la existencia de cláusulas abusivas en las relaciones de consumo hace necesario el establecimiento de mecanismos de control, para recomponer el equilibrio que debe existir entre consumidor y proveedor en estricta observancia del

cláusulas del contrato, o de otro contrato del que dependa.

28 Tovar Mena, Teresa V., op. cit., pag. 50.

${ }^{29}$ Codigo Civil Peruano, Articulo 169. Interpretación Sistemática. Las cláusulas de los actos jurídicos se interpretan las unas por medio de las otras, atribuyéndose a las dudosas el sentido que resulte del conjunto de todas.

${ }^{30}$ Articulo 4.2.- ...la apreciación del carácter abusivo de las clausulas no se referirá a la definición del objeto principal del contrato ni a la adecuación entre precio y retribución, por otra parte, ni a los servicios o bienes que hayan de proporcionarse como contrapartida, por otra, siempre que dichas clausulas se redacten de manera clara y comprensible." 
principio de buena fe objetiva ${ }^{31}$, y garantizar así el respeto irrestricto de los derechos de los consumidores.

\section{EL CONTROL DE LAS CLÁUSULAS ABUSIVAS EN EL DERECHO COMPARADO}

En la legislación comparada podemos encontrar diversos mecanismos de control de las cláusulas abusivas o vejatorias, desde mecanismos de autorreglamentación y concertación, hasta controles administrativos preventivos, control positivo legislativo y control negativo judicial. ${ }^{32}$

En Alemania la Ley (01.04.77) sobre condiciones generales del contrato (Gesetz zur Regelung des Rechts der Allgemeinen Geschäftsbedingungen, $A G B G$ ), regula un modelo de control judicial de las cláusulas vejatorias a través de la implementación de un doble mecanismo de control: una lista de cláusulas que el juez discrecionalmente puede declarar ineficaces (lista gris); y una lista de cláusulas consideradas a priori como absolutamente prohibidas y que por tanto no pueden ser incorporadas en los contratos de consumo (lista negra). ${ }^{33}$

En Francia con la aprobación de la Ley № 78-23 de 1978 se estableció un control administrativo sobre las cláusulas abusivas, pues ciertas cláusulas podían ser prohibidas, limitadas o reglamentadas por decreto emitidos por el Consejo de Estado, previa opinión de una Comisión sobre cláusulas abusivas. Posteriormente, por Ley № 93-949 del 26.07.93 se aprueba el Code de la Consommation, el mismo que es modificado por la Ley № 95-96 del 01.02.95 para adecuarse a la Directica Comunitaria 93/13/CEE; así se incorpora a través de un anexo, una relación indicativa pero no exhaustiva de cláusulas que podrían ser calificadas como abusivas, señalándose que las mismas deben ser consideradas como no puestas, resultando el contrato vigente en sus demás estipulaciones salvo que no pudiera subsistir sin dicha cláusula abusiva. La eliminación de las cláusulas abusivas se deja a la acción de los jueces, quienes podrán solicitar de la Comisión para las cláusulas

${ }^{31}$ Código Civil Peruano, Artículo 1362.- Buena Fe: Los contratos deben negociarse, celebrarse y ejecutarse según las reglas de la buena fe y común intención de las partes.

32 Merino Acuña, Roger Arturo, ob. cit., pag.11.

33 Alpa, Guido, Derecho del Consumidor, Gaceta Jurídica, Lima, Perú, 2004, pags.197 y 198.

${ }^{34}$ Espinoza Espinoza, Juan, ob. cit. pags.166 y 167.

${ }^{35}$ Espinoza Espinoza, Juan, ob. cit. pags.172 a 176.

${ }^{36}$ Artículo 1393.- Cláusulas generales aprobadas por autoridad administrativa.- Las cláusulas generales de contratación aprobadas por la autoridad administrativa se incorporan automáticamente a abusivas, la emisión de un dictamen -no vinculantesobre el carácter abusivo de una cláusula contractual. ${ }^{34}$

La Directiva Comunitaria 93/13/CEE del 05.04.93, recoge las disposiciones del modelo alemán y francés. A través de un anexo, se establece una lista indicativa y no exhaustiva de cláusulas abusivas, a modo de elenco de carácter mínimo, que se podría clasificar de la siguiente manera : Clausulas de desequilibrio entre los derechos y obligaciones de las partes, entre las que encontramos : a) Clausulas relativas a la disponibilidad del vínculo; b) Cláusulas relativas al régimen de responsabilidad del consumidor; c) Cláusulas relativas al régimen de responsabilidad de la empresa; y Clausulas de sorpresa, sobre el vínculo o sobre la regulación. ${ }^{35}$

\section{EL CONTROL DE LAS CLÁUSULAS ABUSIVAS EN EL CÓDIGO CIVIL DE 1984}

El Código Civil distingue entre cláusulas generales de contratación aprobadas por la autoridad administrativa ${ }^{36}$ y cláusulas generales de contratación no aprobadas por la autoridad administrativa ${ }^{37}$, señalándose que la eficacia de estas últimas dependerá de su conocimiento efectivo o posibilidad de conocimiento por la parte no predisponente.

Podemos señalar entonces que en el Código Civil se configuró una suerte de mecanismo de control administrativo, estableciéndose además en el artículo 1394 que "El Poder Ejecutivo señalará la provisión de bienes y servicios que deben ser contratados con arreglo a cláusulas generales de contratación aprobadas por la autoridad administrativa". Lamentablemente no se dictó norma jurídica alguna que señalara cuáles son dichos bienes y servicios, lo que ha llevado a algunos juristas a considerar que el control administrativo consagrado era ambiguo $e$ inoperante. $^{38}$

Al respecto, el Proyecto de Ley de Protección al Consumidor elaborado en 1989 por una comisión designada por el Ministerio de Justicia, establecía en su artículo 31 la obligatoriedad de la contratación con

todas las ofertas que se formulen para contratar con arreglo a ellas, sin perjuicio de lo dispuesto en el artículo 1395.

${ }^{37}$ Artículo 1397.- Cláusulas generales no aprobadas por autoridad administrativa.- Las cláusulas generales de contratación no aprobadas administrativamente se incorporan a la oferta de un contrato particular cuando sean conocidas por la contraparte o haya podido conocerlas usando de una diligencia ordinaria.

Se presume que la contraparte ha conocido las cláusulas generales de contratación cuando han sido puestas en conocimiento del público mediante adecuada publicidad.

38 MERINO ACUÑA, Roger Arturo, ob. cit., pag.12. 
cláusulas generales de contratación aprobadas administrativamente, para el suministro o prestación de los servicios de productos en supermercados o grandes almacenes, agua, teléfono, télex y facsímil, energía eléctrica, combustibles, operaciones bancarias, transporte público de pasajeros, carga y correspondencia.

En la década de los noventa y a partir de la privatización de algunos servicios públicos, el Estado comenzó a ejercer un control a través de los organismos reguladores: OSIPTEL, OSINERG, SUNASS y OSITRAN, entidades administrativas con facultades normativas $y$ fiscalizadoras sobre las empresas privadas que tienen en concesión dichos servicios. ${ }^{39}$

En el caso de los servicios bancarios y financieros, estos también pasaron a ser supervisados por la Superintendencia de Banca y Seguros, la misma que conforme a lo establecido en el artículo 349, inciso 8 de la Ley № 26071, Ley General del Sistema Financiero y del Sistema de Seguros y Orgánica de la Superintendencia de Banca y Seguros, estaba autorizada para realizar un control previo de las CGC. ${ }^{40}$

El mecanismo de control imperante en el Código Civil es básicamente el control positivo legislativo, pues el legislador ha calificado previamente el carácter vejatorio de determinadas cláusulas a través del artículo $1398 .^{41}$

Se ha criticado la disposición antes referida porque excluye del control de las cláusulas vejatorias a las CGC aprobadas por la autoridad administrativa, señalándose que la aprobación no puede ser considerada como una convalidación de la cláusula

39 Al respecto puede revisarse la Resolución № 035-99-CDOSIPTEL, Aprueban cláusulas generales de contratación aplicables al servicio de larga distancia en telefonía fija bajo la modalidad de abonado; la Resolución de Consejo Directivo № 116-2003-CDOSIPTEL, Condiciones de uso de los servicios públicos de telecomunicaciones; la Resolución del Consejo Directivo № 0022000-CD-OSIPTEL, Cláusulas generales de contratación de los servicios públicos móviles; la Resolución de Consejo Directivo № 015-2001-CD- OSIPTEL, Cláusulas generales de contratación de los servicios públicos de difusión y de servicios de valor añadido para acceso a internet.

40 Al respecto puede revisarse la Resolución SBS № 325-2001, Aprueban cláusulas generales de contratación aplicables a los contratos de préstamo hipotecario; la Resolución SBS № 1765-2005 (Noviembre 2005),

Reglamento de transparencia de información y disposiciones aplicables a la contratación con usuarios del sistema financiero; la Ley № 28587 (19.07.2005), Ley Complementaria a la Ley de Protección al Consumidor en materia de servicios financieros.

${ }^{41}$ Código Civil Peruano, Articulo 1398.- Invalidez de estipulaciones. En los contratos celebrados por adhesión y en las cláusulas vejatoria. De otro lado, se cuestionó el limitado esquema de cláusulas consideradas, dado que resulta claramente incompleto, surgiendo la discusión respecto a si se trataba o no de un listado con carácter taxativo, esto es, si estábamos frente a un numerus clausus o numerus apertus; al respecto se señaló que estábamos frente a una lista meramente ejemplificativa, pues se debía hacer una interpretación pro consumidor, acorde con el artículo 65 de la Constitución y posteriormente del artículo 2 del T.U.O. de la Ley de Protección al Consumidor aprobado por el Decreto Supremo N006-2009-PCM.

Al respecto, en las Propuestas de Reformas del Código Civil ${ }^{42}$, al proponerse la modificación del actual artículo 1398, se aludía a las CGC sin distinguir entre aprobadas y no aprobadas administrativamente, y se ampliaba el listado de las cláusulas vejatorias a diez (10), introduciéndose una suerte de cláusula general que permitiera calificar como cláusula vejatoria un número mayor de supuestos.

El Decreto Legislativo № 1045, Ley complementaria del sistema de protección al consumidor, no solo estableció en su artículo 18 una suerte de clausula general abusiva, sino que además considero como no puestas o no pactadas, ciertas cláusulas, condiciones o estipulaciones, que podríamos considerar como vejatorias, y a diferencia del Código Civil, no excluyo de tal posibilidad a las clausulas generales de contratación aprobadas administrativamente. ${ }^{43}$

En lo que sería un mecanismo de control judicial, en aplicación del artículo 1398 del Código Civil, en caso de existir cláusulas vejatorias o leoninas el Juez tendría la facultad de declarar su invalidez, pero se señalaba que

generales de contratación no aprobadas administrativamente, no son válidas las estipulaciones que establezcan, a favor de quien las ha redactado, exoneraciones o limitaciones de responsabilidad; facultades de suspender la ejecución del contrato de rescindirlo o de resolverlo, y de prohibir a la otra parte el derecho de oponer excepciones o de prorrogar o renovar tácitamente el contrato.

${ }^{42}$ Elaboradas por la Comisión Presidida por el Dr. Jorge Avendaño Valdéz y publicadas en el Diario Oficial

El Peruano, el 11.04.2006

43 Ley Complementaria del Sistema de Protección al Consumidor, Articulo 18.- Reglas generales sobre contratos de consumo.- En los contratos entre consumidores y proveedores : ... d. En las cláusulas generales de contratación y en los contratos por adhesión, se tendrán por no puestas las cláusulas que, entre otros, tengan por objeto: (i) Permitir al proveedor modificar unilateralmente las condiciones y términos del contrato en perjuicio del consumidor o sustraerse unilateralmente de sus obligaciones, sin contar con el consentimiento explícito e informado del consumidor; (ii) Establecer la prórroga del contrato sin contar con el consentimiento explícito e informado del consumidor. 
su labor no tendría que limitarse exclusivamente al elenco de cláusulas establecidas en el artículo 1398 C.C., debiendo prevalecer el principio pro consumidor; pero no se precisaba si la declaración judicial de nulidad de la cláusula calificada como vejatoria, afectaba a todo el contrato y aun a los contratos ya celebrados, y si se consideraría no incorporada en los futuros contratos de consumo que se celebrasen.

En las Propuestas de Reformas del Código Civil, antes mencionadas, en la modificación propuesta al artículo 1398 del Código Civil, se sancionaba a las denominadas cláusulas vejatorias o leoninas con ineficacia, no con invalidez ${ }^{44}$.

Finalmente, conforme a lo establecido en el artículo 1400 del Código Civil, en caso de incompatibilidad entre las CGC no aprobadas administrativamente y las cláusulas agregadas a formulario, prevalecen estas últimas; es decir, prevalecen las cláusulas particulares incorporadas por las partes sobre las CGC impresas. Finalmente, de acuerdo a lo señalado en el artículo 1401 del Código Civil, en caso de duda sobre la interpretación de las CGC o de cláusulas incorporadas a formularios previamente redactadas por una de las partes, se deben interpretar a favor de quien no las redactó en aplicación del principio in dubio contra stipulatorem; esto es, frente a la duda se está a favor de quien no redacto las cláusulas.

\section{EL CONTROL DE LAS CLÁUSULAS ABUSIVAS EN EL CÓDIGO DE PROTECCIÓN Y DEFENSA DEL CONSUMIDOR}

En el Código de Protección y Defensa del Consumidor se regula un modelo mixto de control de las cláusulas vejatorias o leoninas, pues se adoptan los tradicionales mecanismos de control administrativo, legislativo y judicial, corrigiendo las carencias del Código Civil y de la legislación de protección al consumidor existente.

\subsection{Control administrativo}

Este mecanismo de control se actúa generalmente cuando las cláusulas aún no se han incorporado a un contrato en particular, de allí su carácter preventivo; en consecuencia, las cláusulas generales de contratación son sometidas a una revisión por parte de la autoridad administrativa correspondiente, la que verificará su

\footnotetext{
${ }^{44}$ Artículo 1398.- Cláusulas vejatorias: En los contratos celebrados por adhesión o con arreglo a cláusulas generales de contratación, son ineficaces las estipulaciones que establezcan, a favor de quién las ha redactado

...."
}

idoneidad para regular relaciones de consumo, y su equidad, esto es, el mantenimiento del equilibrio entre los derechos y deberes de las partes contratantes, específicamente de los consumidores.

En el Código se consagra un control administrativo preventivo que tiene las siguientes características:

\section{a) Autoridad administrativa competente}

Respecto de los servicios públicos sujetos a regulación económica, la aprobación administrativa de las clausulas generales de contratación está a cargo del organismo regulador competente, es decir, SUNASS, OSINERGMIN, OSIPTEL, OSITRAN, respecto de los contratos de consumo celebrados por las empresas prestadoras de dichos servicios públicos, conforme a la ley de la materia y a las disposiciones que el organismo regulador emita al respecto (artículo 54.1).

- En el caso de los servicios financieros y de seguros, la aprobación administrativa de las clausulas generales de contratación corresponde a la Superintendencia de Banca, Seguros y Administradoras Privadas de Fondos de Pensiones, respecto de los contratos celebrados por empresas sometidas a su supervisión (artículo 54.2).

- Existen otras actividades comerciales que no estarían inmersas en un control previo administrativo, como los servicios que se prestan en supermercados o grandes almacenes, o el servicio de transporte de pasajeros y carga, en los que se utilizarían clausulas generales de contratación no aprobadas administrativamente ${ }^{45}$; sin embargo, se señala en el artículo 54.4 del Código que"si con motivo de una investigación efectuada en el ámbito de su competencia, sea en el marco del desarrollo de investigaciones preliminares o de los procedimientos a su cargo, el Indecopi detecta un mercado en el que resulta pertinente la aprobación administrativa de las clausulas generales de contratación, informa de esa circunstancia a la Presidencia del Consejo de Ministros, a la que le corresponde decidir la necesidad de designar una autoridad encargada de ello", en consecuencia, el INDECOPI tendría que señalar progresivamente cuales serían los productos y servicios, cuya adquisición o prestación se realizaría en virtud a contratos de consumo cuyas cláusulas

\footnotetext{
${ }^{45} \mathrm{Al}$ respecto se debe tener en consideración que mediante Ley № 29380 se creó la Superintendencia de Transporte Terrestre de Personas, Carga y Mercancías (SUTRAN), que tiene entre sus funciones normar, fiscalizar y sancionar las actividades de transporte de personas, carga y mercancías, en los ámbitos nacional e internacional.
} 
generales de contratación deberían ser previamente aprobadas por autoridad administrativa.

\section{b) Finalidad del control administrativo}

El control previo administrativo a cargo de la autoridad administrativa correspondiente tendría por finalidad: garantizar en los contratos de consumo la observancia del principio de buena objetiva y el equilibrio entre los derechos y obligaciones de las partes (artículo 48), e identificar las cláusulas abusivas (artículo 54.5), las mismas que no serían aprobadas administrativamente.

c) Difusión de las clausulas aprobadas y de las cláusulas abusivas.

Se establece el deber de la autoridad sectorial de difundir adecuadamente, sea en su portal institucional o a través de otro medio de difusión, las clausulas generales de contratación aprobadas administrativamente y las cláusulas abusivas identificadas como tal por la autoridad administrativa correspondiente (artículo 55), entendiéndose que la difusión alcanza también a las disposiciones o normas de carácter general que la autoridad administrativa hubiera emitido prohibiendo la inclusión de las

\footnotetext{
46 Artículo 50.- Cláusulas abusivas de ineficacia absoluta las siguientes : Son cláusulas abusivas de ineficacia absoluta las siguientes :

a. La que excluyan o limiten la responsabilidad del proveedor o sus dependientes por dolo o culpa, o las que trasladen la responsabilidad al consumidor por los hechos $u$ omisiones del proveedor.
}

b. Las que faculten al proveedor a suspender o resolver unilateralmente un contrato, salvo disposición legal distinta o la aplicación de normas prudenciales debidamente sustentadas emitidas por la autoridad correspondiente.

c. Las que faculten al proveedor a resolver un contrato sin comunicación previa o a poner fin a un contrato de duración indeterminada sin un plazo de antelación razonable, salvo disposición legal distinta o la aplicación de normas prudenciales debidamente sustentadas emitidas por la autoridad correspondiente.

d. Las que establezcan a favor del proveedor la facultad unilateral de prorrogar o renovar el contrato.

e. Las que excluyan o limiten los derechos legales reconocidos a los consumidores, como el derecho a efectuar pagos anticipados o prepagos, o a oponer la excepción de incumplimiento o a ejercer el derecho de retención, consignación, entre otros.

f. Las que establezcan respecto del consumidor limitaciones a la facultad de oponer excepciones procesales, limitaciones a la presentación de pruebas, inversión a la carga de la prueba, entre otros derechos concernientes al debido proceso.

g. Las que establezcan la renuncia del consumidor a formular denuncia por infracción a las normas del presente Código.

h. Las que sean contrarias o violatorias a normas de orden público o de carácter imperativo. clausulas abusiva en los contratos de consumo que se celebren en el futuro (artículo 54.5).

\subsection{Control Legislativo.}

En el Código se consagra también un control legislativo positivo que recogiendo los aportes de la Directiva Comunitaria 93/13/CEE del 05.04.93, tiene las siguientes características:

a) Se desarrolla una cláusula normativa general que contiene una definición de cláusula abusiva (artículo 49.1);

b) Se fijan reglas para la determinación de la existencia de una cláusula abusiva o vejatoria (artículo 49.2);

c) Se consignan dos listados de cláusulas consideradas abusivas: una lista negra que contiene cláusulas que son sancionadas con ineficacia absoluta ${ }^{46}$, y una lista gris que alude a cláusulas que atendiendo al caso concreto podrían ser consideradas como abusivas, por ello se alude a ineficacia relativa ${ }^{47}$, señalándose en este caso que la lista es sólo enunciativa y no taxativa.

Al respecto debemos señalar que en atención a lo dispuesto por el artículo 49.1, se podría interpretar que aun en el caso de las cláusulas abusivas de ineficacia absoluta, estas dejarían de ser tales si se demuestra

47Artículo 51.- Cláusulas abusivas de ineficacia relativa.

De manera enunciativa, aunque no limitativa, son cláusulas abusivas atendiendo al caso concreto las siguientes:

a. Las que impongan obstáculos onerosos o desproporcionados para el ejercicio de los derechos reconocidos al consumidor en los contratos.

b. Las que permitan al proveedor modificar unilateralmente las condiciones y términos de un contrato de duración continuada, en perjuicio del consumidor, salvo que obedezca a motivos expresados en el y el consumidor goce del derecho a desvincularse del mismo sin penalización alguna. Lo dispuesto en el presente literal no afecta las cláusulas de adaptación de los precios a un índice de ajuste legal ni la fijación de tarifas de los servicios públicos sujetos a regulación económica.

c. Las que establezcan la prórroga automática del contrato fijando un plazo excesivamente breve para que el consumidor manifieste su voluntad de no porrogarlo.

d. Las que establezcan cargas económicas o procedimientos engorrosos para efectuar quejas ante el proveedor, así como las que establezcan procedimientos engorrosos para proceder a la reparación del producto no idóneo, o supongan cualquier acto previo o acción por parte del consumidor que imposibilite la debida protección de sus derechos.

e. Las que permitan al proveedor delegar la ejecución de su prestación a un tercero cuando aquel fue elegido por sus cualidades personales.

f. Las que establezcan que el proveedor puede cambiar unilateralmente en perjuicio del consumidor el tipo de moneda con la que fue celebrado el contrato. 
que fueron negociadas individualmente con el consumidor, razón por la cual hubiera sido importante que se considere que las mismas serán siempre ineficaces aunque hubieran sido objeto de negociación previa, como así se dispone en el reformado Código Civil Italiano ${ }^{48}$, que consagra también un régimen de ineficacia relativa (artículo 1469 bis) y de ineficacia absoluta (artículo 1469), además en el artículo 84.2 del Anteproyecto del Código de Consumo ${ }^{49}$ se señalaba que también podían ser declaradas ineficaces por abusivas, aquellas cláusulas contractuales que hubieran sido objeto de tratativa individual. En consecuencia, en aplicación del principio pro consumidor ${ }^{50}$ recogido en el título preliminar del Código de Protección y Defensa del Consumidor, consideramos que en el caso de las cláusulas abusivas de ineficacia absoluta, estas deben ser consideradas inexigibles o ineficaces respecto del consumidor aun cuando hubieran sido objeto de negociación individual.

De otro lado, es cuestionable que en el Código de Protección y Defensa del Consumidor, al igual que ocurre en el Código Civil, se limite en el artículo 49.1 la existencia de cláusulas abusivas a los contratos por adhesión y a las clausulas generales de contratación no aprobadas administrativamente 51 , pudiendo interpretarse la norma en el sentido que en el caso de las clausulas generales de contratación aprobadas administrativamente no existe la posibilidad de que estas sean abusivas, en la medida que han sido revisadas o evaluadas previamente por el Estado, máxime si en el artículo 54.5 se señala que con ocasión de la revisión de las clausulas generales de contratación que se someten a la autoridad administrativa, esta debe identificar las cláusulas abusivas y consecuentemente no aprobarlas, debiendo además disponer que se prohíba su inclusión en contratos futuros ${ }^{52}$; en ese sentido, en el

\footnotetext{
48 Capitulo XIV-BIS De los contratos del consumidor (Capitulo inserto por el art. 25 de la Ley № 52 del

06.02.96), Artículo 1469 quinquies. Ineficacia.- (...) Son ineficaces las cláusulas que, aun cuando hubieran sido objeto de tratativas, tengan por objeto o como efecto :

1) Excluir o limitar la responsabilidad del profesional en caso de muerte o daño a la persona del consumidor, resultante de un hecho u omisión del profesional.

2) Excluir o limitar las acciones del consumidor frente al profesional o a otra parte en caso de in cumplimiento total o parcial o de cumplimiento inexacto por parte del profesional.

3) Prever la adhesión del consumidor como extendida a cláusulas que, en los hechos, no ha tenido la posibilidad de conocer antes de la celebración del contrato.

49 Publicado en el Diario Oficial El Peruano el 18 de octubre de 2009.

50 Articulo V.- Principios. El presente Código se sujeta a los siguientes principios: (...) 2. Principio Pro Consumidor.- En
}

artículo 84.2 del Anteproyecto del Código de Consumo se establecía que podían ser declaradas ineficaces por abusivas, las cláusulas contractuales aprobadas administrativamente. Hay que tener en consideración, sin embargo, que el artículo 48 del Código de Protección y Defensa del Consumidor establece que toda clausula general de contratación -aun las aprobadas administrativamente- debe observar el requisito de buena fe y equilibrio necesario en los derechos y obligaciones de las partes, lo que en todo caso excluye la utilización de cláusulas abusivas, y que conforme a lo señalado en el artículo 54.3 la aprobación general de la cláusula general de contratación solo puede ser cuestionada en la vía judicial, aun cuando luego se prescribe que el consumidor o usuario directamente afectado respecto de la aplicación concreta de la referida clausula puede recurrir ante la autoridad administrativa o judicial competente para que emita pronunciamiento en el caso concreto. En consecuencia, nuevamente aplicando el principio pro consumidor, consideramos que aun en el caso de las clausulas generales de contratación aprobadas administrativamente, estas pueden ser declaradas ineficaces si son calificadas como abusivas.

\subsection{Control Judicial y Arbitral}

Como señala Carlos Cárdenas Quiros ${ }^{53}$, el control judicial puede estar referido a solucionar conflictos relativos a la aplicación e interpretación de cláusulas ambiguas, oscuras o contradictorias, y respecto de la existencia de cláusulas vejatorias.

En el Código de Protección y Defensa del Consumidor se consagra también un mecanismo de control judicial negativo, aun cuando el mismo se extiende también a la autoridad administrativa y a los tribunales

cualquier campo de su actuación, el Estado ejerce una acción tuitiva a favor de los consumidores. En proyección de este principio en caso de duda insalvable en el sentido de las normas o cuando exista duda en los alcances de los contratos por adhesión y los celebrados en base a clausulas generales de contratación, debe interpretarse en sentido más favorable al consumidor.

${ }^{51}$ Artículo 49.1. En los contratos por adhesión y en las clausulas generales de contratación no aprobadas administrativamente, se consideran cláusulas abusivas...

52 Artículo 54.5. En la aprobación de las clausulas generales de contratación, la autoridad administrativa identifica las cláusulas abusivas y emite normas de carácter general que prohíben su inclusión en contratos futuros.

53 CARDENAS QUIROS, Carlos. Las cláusulas generales de contratación y el control de las cláusulas abusivas. En IUS ET VERITAS, Año VII, Número 13, Lima, Perú, setiembre 1996, pag. 31 y 32. 
arbitrales ${ }^{54}$, quienes podrán declarar ineficaces las cláusulas calificadas como abusivas, resultando por tanto inaplicables e inexigibles al consumidor afectado en el contrato especifico, el mismo que sin embargo mantiene su eficacia respecto de las demás clausulas. Al respecto, la declaración de ineficacia no se extiende a todos los demás contratos celebrados que pueda contener idéntica clausula declarada ineficaz, aun cuando por efecto de las decisiones jurisdiccionales, arbitrales $\mathrm{o}$ administrativas adoptadas, en la práctica las mismas no serán exigibles y no serán tampoco incorporadas en los futuros contratos de consumo que celebre el proveedor con los consumidores.

En cuanto al criterio interpretativo contra proferentem recogido en el artículo 1401 del Código Civil ${ }^{55}$, el mismo es aplicable a las relaciones de consumo a tenor de lo dispuesto en el tercer párrafo del artículo 45 del Código de Protección y Defensa del Consumidor ${ }^{56}$, en consecuencia puede ser aplicado por el órgano jurisdiccional, tribunal arbitral o autoridad administrativa, en concordancia con el principio pro consumidor antes referido.

Finalmente, en el Código de Protección y defensa del Consumidor se reconoce legitimación a las Asociaciones de Consumidores, para asumir la defensa de los intereses no solo de sus propios asociados sino también de los intereses colectivos y difusos de los consumidores y usuarios ante los órganos jurisdiccionales y autoridades administrativas; consecuentemente, tienen legitimidad para solicitar la ineficacia de las cláusulas abusivas, sea en la vía administrativa como en la vía judicial conforme a lo dispuesto por el artículo 153 del Código de Protección y defensa del Consumidor ${ }^{57}$.

\section{Conclusiones}

- En el Código de Protección y Defensa del Consumidor se recogen los sistemas tradicionales de control de las cláusulas abusivas o vejatorias,

\footnotetext{
${ }^{54}$ Articulo 52.1 Las cláusulas abusivas ineficaces a que se refiere el presente Código son inaplicadas por la autoridad administrativa. Articulo $52.2 \mathrm{El}$ ejercicio de esta facultad por la autoridad administrativa se hace efectivo sin perjuicio de las decisiones que sobre el particular pueden ser adoptadas en el ámbito jurisdiccional o arbitral, según fuese el caso.

55 Articulo 1401.- Las estipulaciones insertadas en las clausulas generales de contratación o en formularios redactados por una de las partes, se interpretan, en caso de duda, a favor de la otra.

${ }^{56}$ Articulo 45.- (...) En todo lo no previsto por el presente Código o en las leyes especiales, son de aplicación las normas del Código Civil en cuanto resulten compatibles con la naturaleza de estos contratos.

${ }^{57}$ Artículo 153.- Rol de las asociaciones de consumidores.
}

esto es, el control previo administrativo, el control legislativo positivo y el control judicial negativo, corrigiendo los errores del Código Civil y de la legislación preexistente en materia de protección al consumidor.

- El control administrativo previo, en el caso de los servicios públicos sujetos a regulación económica, está a cargo del organismo regulador competente respecto de los contratos de consumo celebrados por las empresas prestadoras de dichos servicios públicos; $y$, en el caso de los servicios financieros y de seguros, corresponde a la Superintendencia de Banca, Seguros y Administradoras Privadas de Fondos de Pensiones, respecto de los contratos celebrados por empresas sometidas a su supervisión; finalmente, el INDECOPI podrá identificar progresivamente los productos $y$ servicios cuya adquisición o prestación se realizaría en virtud a contratos de consumo cuyas cláusulas generales de contratación deberían ser previamente aprobadas por autoridad administrativa, correspondiendo a la Presidencia del Consejo de Ministros decidir la necesidad de designar una autoridad encargada de ello.

- El control legislativo positivo se implementa a través del establecimiento de una cláusula general que contiene una definición de cláusula abusiva, y mediante la elaboración de dos listas (una negra y otra gris) de cláusulas calificadas como abusivas, y sancionadas con ineficacia absoluta e ineficacia relativa, respectivamente, precisándose en este último caso que el listado no es taxativo sino solo enunciativo.

- Se mantiene el control judicial negativo a través de los órganos jurisdiccionales, incluyéndose además a los tribunales arbitrales y a la autoridad administrativa, quienes podrán declarar la ineficacia de las cláusulas abusivas, sean sancionadas con ineficacia absoluta o relativa, en el contrato especifico sometido a examen el mismo

153.1. Las asociaciones de consumidores son organizaciones que se constituyen de conformidad con las normas establecidas para tal efecto en el Código Civil. Su finalidad es proteger, defender, informar y representar a los consumidores y usuarios.

153.2. Las asociaciones de consumidores reconocidas por el Indecopi están legitimadas para interponer reclamos y denuncias ante a Comisión de Protección al Consumidor y los demás órganos funcionales competentes del Indecopi a nombre de sus asociados y de las personas que les hayan otorgado poder para tal efecto, así como en defensa de los intereses colectivos o difusos de los consumidores.

153.3. En la vía judicial pueden promover procesos en defensa de los intereses difusos o colectivos de los consumidores, sujetándose a lo previsto en los artículos 130 y 131. 
que mantiene la eficacia en el resto de sus cláusulas, no extendiéndose dicha sanción a los contratos ya celebrados que contengan similar clausula declarada ineficaz.

- Finalmente, se reconoce la legitimidad de las asociaciones de consumidores para intervenir en defensa de los intereses colectivos y difusos de los consumidores, en la vía judicial y administrativa. 